\title{
Application of a Genetic Algorithm to Optimize Redistribution Process in Zone Refining of Cerium
}

\author{
Huang Jun ${ }^{1,2}, \quad$ Ren Qingbo', Hu Zuqi ${ }^{1}, \quad$ Liu Xun ${ }^{1}, \quad$ Meng Daqiao $^{3}$ \\ ${ }^{1}$ Institute of Materials, China Academe of Engineering and Physics, Jiangyou 621908, China; ${ }^{2}$ Tsinghua University, Beijing 100084, China; ${ }^{3}$ \\ Science and Technology on Surface Physics and Chemistry Laboratory, Jiangyou 621908, China
}

\begin{abstract}
Commercial cerium has been zone refined by induction heating in a cold crucible against the pollution from the crucible materials. A numerical model of solute redistribution during zone refining was integrated into the genetic algorithm (GA) to search after the optimum zone length in different zone passes for increasing the redistribution efficiency of solutes, and the effect of variable distribution coefficient on purification efficiency was also considered in model. The chemical analysis results after 15 zone passes show that the content of $\mathrm{Fe}$ and $\mathrm{Ni}$ at the center of the sample bar are reduced by $50 \%$ and $90 \%$, respectively, and the major difference of these two solutes with close effective distribution coefficient is their initial content. The main difference of experimental results and calculation results is from the instability of shorter zone during later zone passes. Experimental and calculation results show that GA is a powerful tool for looking for optimum of zone lengths in zone passes, but the stability should be maintained in the experiment by an effective method to promote smoothly mobility of solutes in molten zone; the initial content of solutes should be kept as low as possible for getting better purification effect.
\end{abstract}

Key words: cerium; cold crucible; zone refining; genetic algorithm; variable distribution coefficient

Cerium or its alloy has great application in the industry ${ }^{[1,2]}$, but the commercial metal ( $99.5 \mathrm{wt} \%)$ should be further purified before being applied. Zone refining (ZR) and solid state electro-transport (SSE) method are mostly used in the purification of metals after electro-refining, while ZR is more suitable to remove metallic solutes ${ }^{[3]}$. So only zone refining method is considered in this paper.

Since the concept of zone melting was developed by Pfann $^{[4]}$ in 1950s, extensive theoretical and experimental efforts have been carried out to improve the purification efficiency by optimizing experimental parameters such as zone length and zone passes. Rodway ${ }^{[5]}$ had established a criterion for optimizing the zone length during zone refining. The optimization of zone lengths could improve redistribution efficiency of solutes and the criterion was fit for all distribution coefficients $(k)$ which were not equal to unity. $\mathrm{Ho}^{[6]}$ studied the effects of zone lengths and distribution coefficient on separation efficiency in multi-pass processes, and the results showed that the optimum zone length increased with the distribution coefficient but decreased when the zone pass number increased. Spim ${ }^{[7]}$ developed a numerical model of solute redistribution during zone refining process, and the model could be used to predict purification effect of solutes and help to optimize the experimental parameters for improving the purification efficiency. Prasad ${ }^{[8]}$ studied effect of zone passes, zone length and translation rate on the segregation of solute during zone refining. The results showed that zone size of 3 to $6 \mathrm{~cm}$ was optimum for all $k$ and good segregation effect could be achieved at a rate of $30 \mathrm{~mm} / \mathrm{h}$. Cheung ${ }^{[9,10]}$ had analyzed the effect of the distribution coefficient on the redistribution of solute during zone refining $\mathrm{Sb}, \mathrm{Pb}, \mathrm{Sn}$ and $\mathrm{Al}$. The results showed that calculation results of redistribution of solutes in multi-pass zone refining while the variable $k$ was adopted were closer to the experimental profiles than constant $k$. Cheung ${ }^{[11-13]}$ used artificial intelligence technique and genetic algorithm to optimize the varied zone lengths and zone passes, and the 
results showed that the optimization algorithm could be a valuable tool for optimizing zone parameters. Shi ${ }^{[14]}$ had discussed effect of zone length and passes on the segregation efficiency, and the results of zone refining uranium for 10 passes had showed that the distribution efficiency of solutes was mainly depended on the $k$ of solutes. Bochegov ${ }^{[15]}$ developed a software for calculating the distribution at any zone pass and the limiting distribution depending on distribution coefficient and molten zone length.

Cerium metal is very active and easily reacts with container materials. For avoiding contamination from crucible material, Fort ${ }^{[16]}$ had zone refined of rare earth metals (lanthanum, cerium and gadolinium) by radio-frequency $(350 \mathrm{kHz})$ inducing heating in water-cooled boat composed of six segments. Mimura ${ }^{[17]}$ had finished zone refining of the cerium and lanthanum metal within horizontal cold-hearth by plasma arc-zone melting (PZM). Their results showed that zone refining was no obviously effective for redistributing interstitial solutes (such as oxygen, nitrogen, carbon and hydrogen), but was effective for metallic impurities whose $k$ was not equal to unity. Their works do not considered the effect of varied zone length on purification efficiency.

The cold crucible induction melting (CCIM) or inducing skull melting (ISM) is an innovative process, and has great application for processing high purity materials such as aeronautic alloys, medical parts, or nuclear waste recycling ${ }^{[18-21]}$. So in this paper, zone refining of cerium in cold crucible by high frequency induction melting is introduced.

\section{Experiment}

The schematic diagram of the zone refining apparatus is shown in Fig.1. A major consideration in zone refining of cerium is to prevent contamination from the environment and crucible material. In this paper, the mechanicalmolecular pump system is used to gain the high vacuum environment and the limited vacuum of vacuum apparatus was about $5 \times 10^{-5} \mathrm{~Pa}$.

The contamination from crucible material during horizontal zone refining of cerium could be avoided by segmented cold crucible. Based on the results of Deng ${ }^{[22]}$, a cold crucible with 8 segments was designed. The gap between two adjacent copper fingers was $0.8 \mathrm{~mm}$, and the inner and outer radiuses of crucible were 9 and $20 \mathrm{~mm}$ respectively. The both ends of cold crucible were connected to the steel pipe which was driven by motor system. The coil with $8 \mathrm{~mm} \times 8 \mathrm{~mm} \times 1 \mathrm{~mm}$ section was wrapping around the cold crucible 3 loops along radius direction and was connected to coaxial electrode. The total power of electric source was $60 \mathrm{~kW}$ and the working frequency was $50 \mathrm{kHz}$. The power output is regulated to produce the varied zone lengths during different zone passes, and temperature of

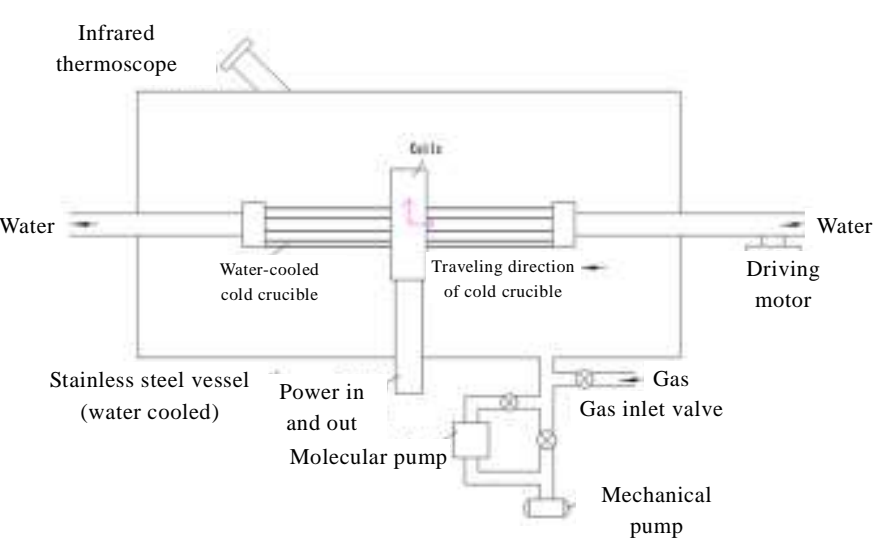

Fig. 1 Schematic diagram of zone refining by induction heating in cold crucible

molten metal was tested by infrared thermometer. A slow speed $(18 \mathrm{~mm} / \mathrm{h})$ of molten zone was chosen for getting an effective distribution coefficient $\left(k_{\text {eff }}\right)$ close to $k$.

The cerium bar with $\Phi 17 \mathrm{~mm} \times 200 \mathrm{~mm}$ was zone refining for 15 passes in high vacuum environment. The surface oxide layer of zone refined cerium bar was cleaned away before next pass.

For evaluating the redistribution behavior of metallic impurities in cerium, the initial contents of 4 solutes (Al, Fe, $\mathrm{Cu}$ and $\mathrm{Ni}$ ) were analyzed before zone refining. After 1st and 15th zone pass separately, the samples were milled from 5 positions $(10,50,100,150,190 \mathrm{~mm}$ away from the head face of bar). Because the atom emission spectrum lines of cerium were much and may interfere with those of solutes, cerium should be separated from solutes. The samples were dissolved by $\mathrm{HNO}_{3}$ and hydrogen peroxide, and then cerium was separated by dissolved gas analysis (DGA) extraction chromatographic column. Then the liquid after separating was sent for chemical analysis by inductively Coupled Plasma-Atom Emission Spectrum (ICP-AES).

\section{Numeric Model}

\subsection{Numeric model of solute redistribution}

The numeric model is based on the Spim's model of solute redistribution during zone refining ${ }^{[7]}$, and the main deducing process is as follows. Before introducing the numeric model, some parameters are defined here. $C_{0}$ is the initial content of solute and $C_{\mathrm{S}}$ is content of solute after solidification. $X$ is the relative distance of position away from the head face of bar, and $Z$ is relative length of zone length. $\mathrm{d} X$ is the least computing element, and $M$ is all number of $\mathrm{d} X$ within $X$. The $p$ is integer variable and $n$ is the number of zone pass.

After one pass of zone refining is completed, the composition distribution of solute along bar except for the 
last zone length will be given as follows:

$$
C_{\mathrm{s}} / C_{0}=1-(1-k) \exp (-k X / Z)
$$

The classical Scheil equation can be used to show the distribution of solute in the last zone length of bar where normal solidification takes place:

$$
\begin{aligned}
& C_{\mathrm{s}} / C_{0}=\{1-(1-k) \exp [-k(1-Z) / Z]\} \times \\
& \{1-[X-(1-Z)] / Z\}^{k-1}
\end{aligned}
$$

Based on Eqs. (1) and (2), the distribution of solute at any position in bar along axial direction during later zone passes can be deduced. The four different regions along the sample are considered as follows.

Region 1, head face $(X=0)$ :

$$
C_{S(0)}^{n}=k \mathrm{~d} X / Z\left(\sum_{p=0}^{M-1} C_{S(p \cdot \mathrm{d} X)}^{n-1}\right)
$$

where, $M$ is number of $\mathrm{d} X$ in $Z$ along axial direction. Region 2 , intermediate part $(0<X<=1-Z)$ :

$$
\begin{aligned}
& C_{S(X)}^{n}=C_{S(X-\mathrm{d} X)}^{n}+ \\
& k \mathrm{~d} X / Z\left[C_{S(X+Z-\mathrm{d} X)}^{n-1}-C_{S(X-\mathrm{d} X)}^{n}\right]
\end{aligned}
$$

Region 3, last zone length $(1-Z<X<1)$ :

$$
\begin{aligned}
& \left.C_{S(X)}^{n}=C_{S X-X \mathrm{~d}}^{n}\right)^{+} \\
& \left(1-k \varnothing \quad\left(-1 X C_{\left.b_{(X-\mathrm{d} X}\right)}^{n} X(\right.\right.
\end{aligned}
$$

Region 4, end face $(X=1)$ :

$$
\left.C_{S}^{n}=C_{0}-\sum_{p=0}^{M-1} C_{S(p \cdot X}^{n} /\right)^{\prime}
$$

A numeric model of solute redistribution during zone refining can be built from Eqs. (1) to (6) by a finite difference method. After zone refining, the distribution of solute will be varied along cerium bar, and the constant $k$ is not fit for predicting the distribution of solutes especially in both ends of bar. So, varied $k$ is used in the numeric model.

In experiment, the equilibrium distribution coefficients $(k)$ of solutes are displaced by $k_{\text {eff }}$, and the $k_{\text {eff }}$ have been defined as BPS relation ${ }^{[4]}$ :

$$
k_{\text {eff }}=k /\left(k+(1-k) \exp \left(-\frac{V \delta}{D}\right)\right)
$$

where, $D$ is the impurity diffusivity of solutes in the molten metal, $\delta$ is the thickness of the diffusion layer of solutes in molten zone adjacent to the solidification interface, and $V$ is the molten zone travelling speed. $\delta$ depends on fluid mixing conditions, the diffusion coefficient of solute and the kinematic viscosity of the liquid. If diffusion is the only mixing process, the diffusion layer is of the order of the zone length; but if vigorously mixing molten zone, the diffusion layer is close to zero. Generally, actual transferring condition is between two cases above, and enough slow $V$ is chosen in the experiment for getting a $k_{\text {eff }}$ close to $k^{[7]}$.
When the zone length is defined, and the number of zone passes can be predicted by the semi-empirical formula ${ }^{[23]}$ as follows:

$$
n=(1-1.5) / Z
$$

Some published works showed that 15 zone passes would be necessary to achieve better purification and was assessed to be a practicable minimum number of zone passes ${ }^{[16]}$. In this paper, 15 zone passes are carried out in experiment and the zone lengths in different zone pass are optimized by GA for getting purification efficiency.

\subsection{Zone length optimized by GA}

Zone length is one of the key parameters in zone refining process, which can affect the ultimate distribution and the speed it is approached. In this paper, the variable zone lengths for 15 zone passes are optimized by GA for getting the maximization of redistribution efficiency of solutes.

GA is a stochastic optimization algorithm derived from the idea of evolutionary biology. The main step of GA is initialization, selection, crossover and mutation ${ }^{[24]}$.

\subsubsection{Initialization}

The initial population for the question should be generated. It is not known how close the optimized individual is to the global optimum, but it is expected that the answer to the problem given by GA will be in the vicinity of it. A large number of individuals are chosen as the population of first parent generation. The zone lengths for 15 zone passes are stochastically produced by a real number encoding method according to the descending order. The object function of GA minimizes the content of solute, or maximizes purity of cerium in the middle part of bar. The purification efficiency of each individual is calculated in the numeric model of solute redistribution during zone passes. Then the fitness of single individual can be got when its purification value is divided by the sum of that of all individuals, and individual whose fitness is maximization is the best individual.

After the initialization and evaluation of individual in first father population, regeneration of offspring is produced by the genetic evolution principle.

\subsubsection{Selection}

According to the strife to survival, individuals with larger fitness will gain much opportunity of survival and breeding, and these individuals are added into the new population by a bet wheel method.

\subsubsection{Crossover}

Next, the single point crossover method is chosen for producing new individual through any two individual in new population. The probability operator of crossover (Pc) is the main search operator in GA. Generally, a too large Pc may destroy the excellent pattern which has been formed and the probability for searching is too large; but a small Pc may decrease the velocity for searching new individual with good fitness. Then a Pc with a relatively large value in this 
study is used, and the population is stochastically divided into 2 arrays with the same number. The individual of every pairs are intercrossing by single point within Pc. If the fitness of individual produced by crossover operator is bigger than that of the best individual, the best individual will be replaced.

\subsubsection{Mutation}

Then, the mutation of individual in current generation is implemented by a stochastic value with a small probability $(\mathrm{Pm})$. If the fitness of individual produced by mutation operator is bigger than that of the best individual, the best individual will be replaced.

\subsubsection{Evolution of GA}

As three steps mentioned above are conducted, one time of the genetic evolution is finished. Then, the fitness of individual in new generation is calculated and evaluated, and the individual with best fitness is got.

Next, the new genetic evolution is continued until the number of times for genetic evolution is bigger than the number defined, or the individual with best fitness is not changed for many generations. At last, the individual with best fitness will be the optimum of zone length for zone refining process.

Based on the apparatus of zone refining, the range of zone lengths is chosen between $15 \mathrm{~mm}$ with $60 \mathrm{~mm}$ in numeric model.

\section{Results and Discussion}

The cerium bar is prepared at ZhongNuo Advanced Material Technology Co., Ltd. The initial contents of 4 typical solutes $(\mathrm{Al}, \mathrm{Fe}, \mathrm{Cu}$ and $\mathrm{Ni})$ in cerium metal are shown in Table 1.

The relative content $\left(C_{\mathrm{s}} / C_{0}\right)$ of $\mathrm{Al}$ at 5 positions on bar along axial direction after 1 st and 15 th zone pass are shown in Fig.2. After the 1st zone pass, the content of $\mathrm{Al}$ at head part of bar is decreased about to $70 \%$, then gradually increased to 1 , and is rapidly increased larger than 1 after about $75 \%$ of cerium bar. After 15 th zone pass, the content of $\mathrm{Al}$ at the head part of bar is further decreased and is about $30 \%$ at the head end, and is about to $50 \%$ at center part.

For assessing the redistribution efficiency of $\mathrm{Al}$ in cold crucible by induction zone refining at high vacuum atmosphere, the distribution of $\mathrm{Al}$ along axial direction of bar is calculated. During zone refining process, the content of solutes along axial direction is varied widely, especially at two end parts. Then the constant $k$ might be not fit for calculating all positions on bar, and the varied $k$ is also considered in calculation. In this paper, 3 kinds of experiment parameters are calculated shown in Fig. 2. The shortest zone length in experiment at later zone passes is longer than $25 \mathrm{~mm}$, and the main reason is that shorter zone length could not be easily controlled and the molten zone is
Table 1 Initial contents of 4 kinds of impurities in cerium $(\mu \mathrm{g} / \mathrm{g})$

\begin{tabular}{ccccc}
\hline Impurity & $\mathrm{Al}$ & $\mathrm{Fe}$ & $\mathrm{Cu}$ & $\mathrm{Ni}$ \\
\hline Content & 967 & 998 & 110 & 33 \\
\hline
\end{tabular}

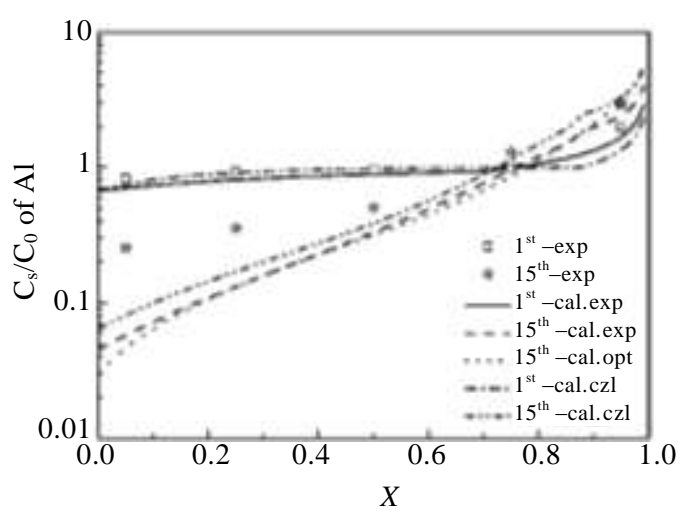

Fig.2 Redistribution of $\mathrm{Al}$ after zone refining along cerium bar

prone to unstable in high vacuum environment. The calculation results show that the redistribution efficiency of solute when varied zone length is used is better than that when constant zone length is used, but the effect of shorter zone length in later zone passes is not obvious. It might be concluded that bigger zone length is benefit for solute whose distribution coefficient is close to unity, and the $k_{\text {eff }}$ of $\mathrm{Al}$ is about 0.65 .

The redistribution efficiency of $\mathrm{Al}$ after 15 zone passes in experiment is lower than that of calculation. The reason might be from the instability of molten zone in high vacuum especially in later zone passes. Fort ${ }^{[16]}$ found that the molten zone is instability in high vacuum environment, but the molten zone could be stabilized in ultra high argon atmosphere. The difference between vacuum and argon environment might be that there is an argon gas membrane between the molten metal and cold crucible, and thermal resistance of gas membrane retarding the thermal exchanging process between molten metal and cold crucible.

The symbol of hollow rectangle ( $\square$ ) and star (ㅊ) express the experiment results after 1 st and 15 th zone pass separately. The annotation of -cal.exp. shows the calculation results when the experiment parameters and varied distribution coefficient are used in the numeric model. The annotation of -cal.opt. shows the calculation results when the varied zone length optimized by GA and varied distribution coefficients are used in the numeric model. The annotation with -cal.czl. shows the calculation results when the constant zone length is only used in numeric model.

The experiment testing results and calculation results of $\mathrm{Fe}$ are shown in Fig.3. The redistribution effect of $\mathrm{Fe}$ is better than that of $\mathrm{Al}$, and its $k_{\text {eff }}$ is about 0.42 which is 


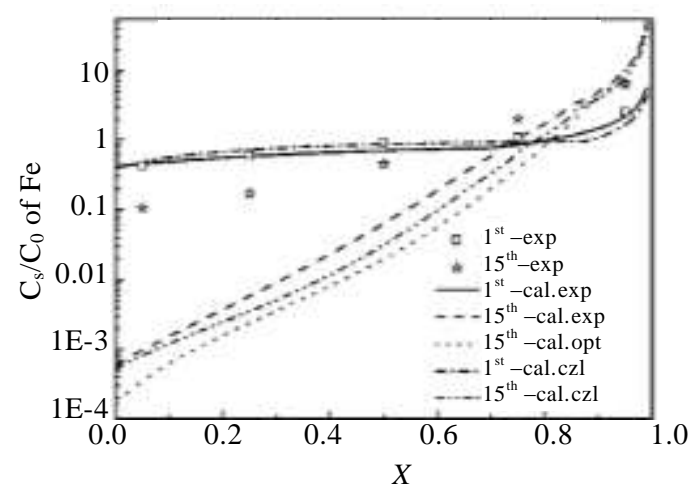

Fig.3 Redistribution of Fe after zone refining along cerium bar

evaluated by the experiment results after 1 st zone pass. The content of $\mathrm{Fe}$ at head end of bar is decreased about to $10 \%$ and is decreased about to $40 \%$ at center part of bar after 15 th zone pass. Difference from that of $\mathrm{Al}$, the calculation results of $\mathrm{Fe}$ with the experimental zone length is higher than that with constant zone length. This result has shown that the shorter zone length should be used in later zone pass for increasing segregation effect of solutes whose $k$ is far away from unity.

The experiment testing results and calculation results of $\mathrm{Cu}$ are shown in Fig.4. The $k_{\text {eff }}$ of $\mathrm{Cu}$ is about 0.45 evaluated from the experiment results after 1st zone pass, which is very close to that of Fe. In this experiment condition, the content of $\mathrm{Cu}$ does not increase after 15 zone passes, and the results has shown that segmented copper crucible cooled by water can be used as a container for zone refining active metal such as cerium.

As shown in Fig.5, the redistribution of Ni after 1st zone pass is similar to that of $\mathrm{Fe}$ and $\mathrm{Cu}$, but there is remarkable difference after 15 th zone pass. The content of $\mathrm{Ni}$ at the head end of bar is decreased about to $0.3 \%$ of its initial content, and gradually increased to $10 \%$ at center part of bar after 15 th zone pass.

The $k_{\text {eff }}$ of $\mathrm{Ni}$ is about 0.35 evaluated from the experiment results after 1 st zone pass, which is close to that of $\mathrm{Fe}$. The properties of $\mathrm{Fe}$ and $\mathrm{Ni}$ are similar because their sites located in periodic table of elements are close. But the experiment results of $\mathrm{Ni}$ are very different from that of $\mathrm{Fe}$. The main difference between $\mathrm{Ni}$ with $\mathrm{Fe}$ is their initial content in cerium. From the experimental results of $\mathrm{Fe}$ and $\mathrm{Ni}$, we can consider that solute whose initial content is much has low purification efficiency and is susceptible to surrounding condition. Then, initial content of solute should be reduced as low as possible.

Cold crucible by high frequency induction has great advantages in melting high activity, or high melting point material. But there are some troubles when a horizontal cold crucible is used for zone refining of reactive materials

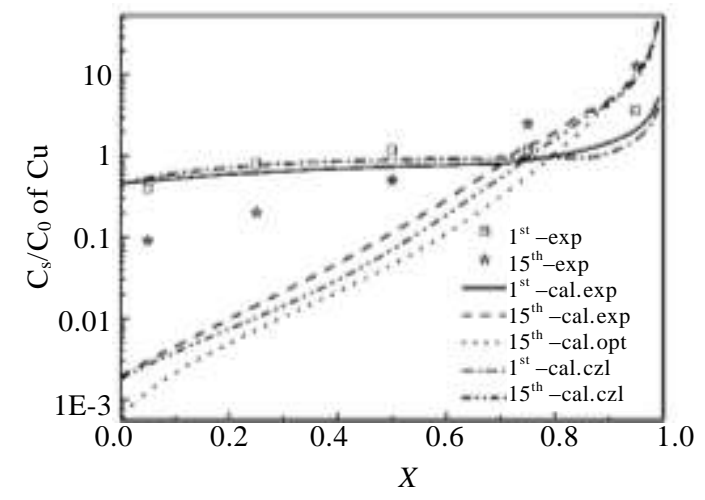

Fig.4 Redistribution of $\mathrm{Cu}$ after zone refining along cerium bar

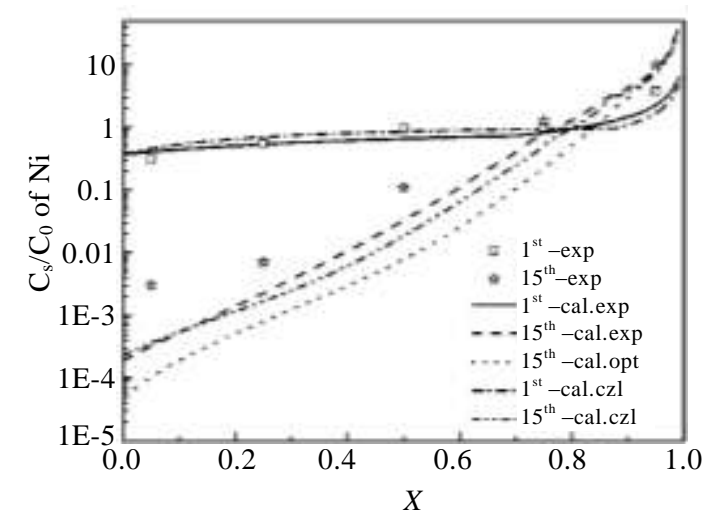

Fig.5 Redistribution of Ni after zone refining along cerium bar

such as cerium and lanthanum metal in high vacuum. As shown in this paper, the instability of molten zone in shorter zone refining greatly decreases redistribution efficiency of solutes during zone refining especially for solutes whose initial content are much. An option proposed by Fort ${ }^{[16]}$ is that rare earth metal is melted in ultra high vacuum environment and then zone refined in high purity argon atmosphere, but this method might sacrifice the advantage of high vacuum melting during zone refining. In this experiment, the high purity argon (purity 99.999\%) is tried, but molten zone is easily oxidized and ultra high purity argon should be used in later experiment.

Another trouble during zone refining of metal in cold crucible is that it is difficult to get shorter molten zone during later zone passes. This question might be related with the instability of molten zone in high vacuum, or might be from the divergence of magnetic field around coils. Instability of molten zone can be answered when zone refining in argon environment. And the divergence of magnetic field can be overcome by modifying the coils and cold crucible. For increasing the heat efficiency of cold crucible, an optimum cold crucible similar with that proposed by Ernst ${ }^{[25]}$ may be tried in future. 


\section{Conclusions}

1) The content of $\mathrm{Cu}$ after zone refining does not increase, and then the cold crucible can be used as a container for zone refining of active metals such as cerium.

2) The initial content of solutes has important effects on redistribution behavior, and should be kept as low as possible before experiment for better purification efficiency.

3) Larger zone length in early zone passes and shorter zone lengths in later zone passes can increase segregation efficiency of solutes during zone refining especially for solutes whose $k$ are far away from the unity.

4) The GA is a useful tool of getting the optimized zone lengths during zone refining, but the stability of molten zone should be maintained in cold crucible.

Acknowledgements: The authors would like to acknowledge the help from Qin Zhen and Wang Huaisheng for chemical analysis of samples.

\section{References}

1 Lin H C. China Nonferrou Metall[J], 2005(3): 31 (in Chinese)

2 Bouzigues C, Gacoin T, Alexandrou A. Acsnano[J], 2011, 5(11): 8488

3 Wu S Z, Wang T H, Xu F et al. Rare Metal and Cemented Carbides[J], 2013, 41(4): 10

4 Pfann W G. Zone Melting[M]. New York: Willy, 1958: 55

5 Rodway G H, Hunt J D. Journal of Crystal Growth[J], 1989, 97(3-4): 680

6 Ho C D, Yeh H M, Yeh T L. Separation and Purification Technology[J], 1999, 15: 69

7 Spim J A, Bernadou M J S, Garcia A. Journal of Alloys and Compounds[J], 2000, 298: 299

8 Prasad D S, Munirathnam N R, Rao J V et al. Materials Letters[J], 2006, 60: 1875
9 Cheung N, Bertazzoli R, Garcia A. Separation and Purification Technology[J], 2007, 52: 504

10 Cheung N, Bertazzoli R, Garcia A. Journal of Crystal Growth[J], 2008, 310: 1274

11 Cheung T, Cheung N, Garcia A. J Electron Mater[J], 2010, 39(1): 49

12 Cheung T, Cheung N, Tobar C M T et al. Materials and Manufacturing Processes[J], 2011, 26: 493

13 Cheung T, Cheung N, Tobar C M T et al. Materials and Manufacturing Processes[J], 2013, 28(7): 746

14 Shi J, Luo C, Zhang X J et al. Rare Metal Materials and Engineering[J], 2013, 42(4): 833 (in Chinese)

15 Bochegov V I, Parakhin A S. Tech Phys Letter[J], 2014, 40(6): 460

16 Fort D, Jones D W, Beaudry B J et al. J Less-Common Met [J], 1981, 81: 273

17 Mimura K, Sato T, Isshiki M. J Mater Sci[J], 2008, 43: 2721

18 Morita A, Fukui H, Tadano H et al. Mater Sci Eng A [J], 2000, 280: 208

19 Hong S W, Min B T, Song J H et al. Materials Science and Engineering $A[\mathrm{~J}], 2003,357(1-2): 297$

20 Chen R R, Guo J J, Chen X Y et al. China Foundry [J], 2014, 11(4): 332 (in Chinese)

21 Dong S L, Chen R R, Guo J J. Mater Design[J], 2015, 67: 390

22 Deng K, Ren Z M, Chen J Q et al. Chinese Journal of Computation Physics[J], 2000, 17(6): 659 (in Chinese)

23 Liang Y Q, Li G D, Yun Y H. Acta Scientiarum Naturalium Universitatis Neimongol[J], 2002, 33(3): 257 (in Chinese)

24 Zhou M, Sun S D. Genetic Algorithm: Theory and Applications[M]. Beijing: National Defense Industry Press, 1996 (in Chinese)

25 Dumont M, Ernst R, Garnier C et al. Journal of Iron and Steel Research, International[J], 2012(2): 669

\title{
遗传算法优化区熔铈的再分配过程
}

\author{
黄 俊 ${ }^{1,2}$, 任清波 ${ }^{1}$, 胡祖麒 ${ }^{1}$, 刘 勋 ${ }^{1}$, 蒙大桥 ${ }^{3}$ \\ (1. 中国工程物理研究院, 四川 江油 621908) \\ (2. 清华大学, 北京 100048) \\ (3. 表面物理与化学重点实验室, 四川 江油 621908)
}

\begin{abstract}
摘 要: 通过冷坩埚感应区熔提纯钥以避免坩埚材料的污染。溶质再分配数值模型结合遗传算法 $(\mathrm{GA})$ 搜寻优化区熔参数以提高溶质的 再分配效率, 并考虑变溶质分配系数对计算结果的影响。15 次区熔后的化学结果分析显示, 具有相近分配系数的 $\mathrm{Fe}$ 和 $\mathrm{Ni}$ 在试棒中部 分别降低 50\%和 $90 \%$, 主要差别为初始含量不同。实验结果和计算结果的主要差别源于后续区熔实验过程中较窄熔区的不稳定。研究 结果表明, GA 是一种获得最优熔区长度的有力工具, 但是需要采取有效办法获得稳定的熔区以促使杂质顺利迁移, 另外杂质的初始 含量应尽可能降低以获得好的提纯效果。
\end{abstract}

关键词: 铈; 冷坩埚; 区熔; 遗传算法; 变分配系数

作者简介: 黄 俊, 男, 1975 年生, 博士生, 高级工程师, 中国工程物理研究院材料研究所, 四川 江油 621908, 电话: 0816-3626782, E-mail: huangjun1@caep.cn 